\title{
TELEMEDICINE AND OPHTHALMOLOGY PRACTICE IN THE COVID-19 ERA
}

\author{
Mahmoud, H. ${ }^{1(*)}$ \& Abd El-Badie, M. $^{2}$ \\ ${ }^{1}$ Ophthalmology dept., Faculty of Medicine, Sohag Univ., Sohag, Egypt \\ ${ }^{2}$ Ophthalmology dept., Faculty of Medicine, Al-Azher Univ., Assuit, Egypt \\ E-mail:drhanymahmoud@gmail.com
}

\begin{abstract}
Purpose: To evaluate telemedicine practice in ophthalmology between samples of Egyptian ophthalmologists; their current, prospective use in the era of COVID-19, satisfaction and limitations. Methods: An internet- based questionnaire was administered to Egyptian ophthalmologists. A total of 1857 participated in the internet-based questionnaire. Full ethical considerations are fully followed; Sohag university hospitals research committee protocol. Results: 46 percent of the responders were using telemedicine. Sense of satisfaction of physician and patient were $51.6 \%$ and $52.5 \%$. The major obstacle for practicing telemedicine is patient awareness $54.4 \%$, followed by technology infrastructure problems $44.6 \%$. Conclusion: Telemedicine is a good method, especially in that era, many ophthalmologists actually use it, others will hasten their practice, and the limitations are emergencies, awareness between patients and some physicians. Ophthalmologists need more telemedicine training.
\end{abstract}

Keywords: Telemedicine, COVID-19, Technology, Training, Lmitations

\section{Introduction}

Telemedicine incorporates technologies (ICT) and activities that offer modern methods to deliver medical care. Telemedicine provides beneficial services by using ICT when health professionals and patients are distant. Telemedicine allows the confidential transmission of medical information (texts, sounds, images, etc.) [1]. It was considered an experimental dream some years ago, but it is a reality today due to rapid improvement in the quality of new technologies as well as impressive gains in internet speed and quality [2]. With the onset of the COVID19 pandemic worldwide, the process of shifting medical care to telemedicine visits has increased [3]. Telemedicine includes four main areas: [4] First; live or simultaneous audio-video telemedicine, i.e. bidirectional interaction between a patient and a physician using audiovisual technologies with data collection. Second, store-andforward or asynchronous telemedicine (freely translatable as "store and return"), which is a technique in which information subdivided into clusters in its path between the single points of the safe digital network, should be totally at first received before it can be retransmitted again to the source. Third, over distance patient monitoring, i.e. coll- 
ection of health data directly from the patient, usually during the normal activities of daily life, is digitally transmitted to a physician for analysis and effective actions making and finally, mobile communication platforms for advice. Telemedicine has multiple applications in ophthalmic practice because it needs visual images for diagnosis, treatment, and follow-up of the diseases. [5]. For example, telemedicine may improve the quality of health care in some important ophthalmological diseases, such as diabetic retinopathy (DR) and retinopathy of prematurity (ROP). Telemedicine programs provide screening for patients with DR in primary assistance [6]. Image-based telemedicine is an accurate and low-cost technique for ROP in premature babies [7]. Telemedicine in ophthalmic practice is useful

\section{Methodology}

A cross-sectional study was conducted among Egyptian ophthalmologists in June 2020. The survey included ophthalmologists from nearly all Egyptian governorates. We designed an internetbased questionnaire survey addressing the issue in 10 separate questions, which were: 1) Do you practice telemedicine now or before? (If no, please do not complete the survey) 2) How? 3) Were

\section{Results}

The survey results are shown in tab. (1). A total of 1857 participants were enrolled in the survey. 1002 (54\%) of which give 'No' answers to the first question and did not complete the questionnaire. 855 (46\%) participants completed the questionnaires. $(50.2 \%)$ and $(49.8 \%)$ of the participants used phones and smart applications, respectively, in telemedicine. $(51.6 \%)$ of the participants were satisfied with telemedicine, while $(52.5 \%)$ think that the patients were satisfied too. A majority of the responders (76.8\%) will consider it in their current and future practice. A percentage of $(75.3 \%)$ of the for intraocular pressure monitoring and evaluation in glaucoma patients and macular diseases. Finally, remote consultations and examinations, instead of face-to-face, are gaining more ground thanks to two-way communication technologies in emerging clinical institutions [8]. However, there are multiple challenges to realizing its full potential, such as medico-legal and ethical issues such as doctor-patient relationship, informed written consent, rights of the patient, malpractice, and principles of confidentiality relevant to the practice of telemedicine and virtual consultation [9]. The aim of this work is to evaluate telemedicine practice in ophthalmology regarding possibilities, techniques, methods, and possible limitations.

you satisfied? 4) Do you think the patient was satisfied? 5) Will you consider it in your current and future practice? 6) Do you think it is suitable for all medical ophthalmology conditions (except surgical and emergency)? 7) Do you think that it will enforce social distances and protect ophthalmologists? 8) What are the obstacles? 9) Do you need instruction courses? 10) Kindly write your governorate.

responders thought it was suitable for all medical ophthalmology conditions (except surgical and emergency). (77.4\%) of the responders think it will enforce social distances and protect ophthalmologists. The participants think the major obstacle for practicing telemedicine is patient awareness $(54.4 \%)$, followed by technology infrastructure problems $(44.6 \%)$. A percentage of $(61.2 \%)$ of the responders informed that they may need instruction courses in telemedicine. The 10th question was a demographic one asking participants to write down their governorate. 
Table (1) Results of the cross-sectional survey conducted among Egyptian ophthalmologists in June 2020

\begin{tabular}{|c|c|c|c|}
\hline Questions & \multicolumn{3}{|c|}{ Results of the cross-sectional survey } \\
\hline \multirow{2}{*}{$\begin{array}{l}\text { 1. Do you practice telemedicine now or } \\
\text { before? (If no please don't complete the } \\
\text { survey) }\end{array}$} & Yes & No & \\
\hline & $855(46)$ & $1002(54)$ & \\
\hline \multirow[t]{2}{*}{ 2. How? } & Phone & Smart applications & \\
\hline & $429(50.2)$ & $426(49.8)$ & \\
\hline \multirow[t]{2}{*}{ 3. Were you satisfied? } & Yes & No & \\
\hline & $441(51.6)$ & $414(48.4)$ & \\
\hline \multirow[t]{2}{*}{ 4. Do you think the patient was satisfied? } & Yes & No & \\
\hline & $449(52.5)$ & $406(47.5)$ & \\
\hline \multirow{2}{*}{$\begin{array}{l}\text { 5. Will you consider it in your current and } \\
\text { future practice? }\end{array}$} & Yes & No & \\
\hline & $657(76.8)$ & $198(23.2)$ & \\
\hline \multirow{3}{*}{$\begin{array}{l}\text { 6. Do you think it's suitable to all medical } \\
\text { ophthalmology conditions (except } \\
\text { surgical and emergency)? }\end{array}$} & Yes & No & \\
\hline & & & \\
\hline & $644(75.3)$ & $211(24.1)$ & \\
\hline \multirow{2}{*}{$\begin{array}{l}\text { 7. Do you think that it will enforce social } \\
\text { distances and protect ophthalmologists? }\end{array}$} & Yes & No & \\
\hline & $662(77.4)$ & $193(22.6)$ & \\
\hline \multirow[t]{2}{*}{ 8. What are the obstacles? } & Patient awareness & Doctor awareness & $\begin{array}{l}\text { Technology } \\
\text { infrastructure }\end{array}$ \\
\hline & $465(54.4)$ & $18(2)$ & $382(44.6)$ \\
\hline \multirow[t]{2}{*}{ 9. Do you need instruction courses? } & Yes & No & \\
\hline & $523(61.2)$ & $332(38.8)$ & \\
\hline
\end{tabular}

Values are $n(\%)$.

\section{Discussion}

The ongoing COVID-19 pandemic has made humanity face an increasing need for social distancing. In the challenge of this global pandemic, efficient and safe medical care can be applied by telemedicine. Practicing telemedicine in ophthalmology is particularly interesting as it is considered to be one of the "visually intensive" specialties [10]. Although that it is considered to be a novel innovative practice, $46 \%$ of the physicians were practicing telemedicine in ophthalmic daily practice. This percentage is quite high, but most likely because Telemedicine has been promoted as a strategy for improving accessibility to health care [11], especially during the quarantine in the Era of Covid-19.Moreover,the presence of smart phones and easy smart applications for both physicians and patients were quite equal $(50.2 \%)$ and $(49.8 \%)$, respectively. Physicians and patient selfsatisfaction were $(51.6 \%)$ and $(52.5 \%)$ [12]. Most of the responders $(75.3 \%)$ agreed that it was suitable for all medical ophthalmology conditions (except surgical and emergency). This is because ophthalmology is a specialty that relies mostly on digital images and technology for diagnosis and treatment. In particular, as technology increasingly offers us the quality of information transfer, we require for make safe and reliable clinical decisions [13]. Therefore, many ophthalmologists a considerable will apply it in their future practice. Social distancing measures are taking place around the world, which can markedly inhibit widespread dissemination of the virus [14]. Therefore; $(77.4 \%)$ of the responders 
thought that it would protect ophthalmologists as it enforces social distancing. As the subject grows, courses are now available in telemedicine [15] and a considerable number of the responders $(61.2 \%)$ reported that they may need instruction courses in telemedicine.

\section{Conclusion}

Telemedicine is currently used in ophthalmology practice.lt will take a big role in the era of COVID-19, and many ophthalmologists find it good method for social distance and infection avoidance, other ophthalmologists need some training courses, patient awareness remains an obstacle; we need to widen the scope.

\section{References}

1. Communication from the commission to the European parliament, the council, the European economic and social committee and the committee of the regions on telemedicine for the benefit of patients, Healthcare Systems And Society. Brussels, COM (2008) 689 final. [4.11.2008]; Commission of the European. Communities.

2. Waller M., Stotler C. Telemedicine: A Primer. Curr Allergy Asthma Rep. 2018; 18 (10): 54., doi:10.1007/s11882-018-

3. Waller M., Stotler C. Telemedicine: A Primer. Curr Allergy Asthma Rep. 2018; 18 (10): 54. doi:10.1007/s11882-0180808-4

4. Gioia G., Salducci M. Medical and legal aspects of telemedicine in ophthalmology. Rom J Ophthalmol. 2019; 63 (3): 197-207.

5. Morse A. Telemedicine in ophthalmology: promise and pitfalls. Ophthalmol. 2014; 121 (4): 809-811.

6. Zheng Y., He M., Congdon N. The worldwide epidemic of diabetic retinopathy. Indian J Ophthalmol. 2012; 60 (5): 428-431.

7. Richter G., Williams S., Starren J., et al. Telemedicine for retinopathy of pre- maturity diagnosis: Evaluation and Challenges. Surv Ophthalmol. 2009; 54 (6): 671-685.

8. Gan K., Liu Y., Stagg B., et al. Telemedicine for glaucoma: Guidelines and Recommendations. Telemed J E Health. 2020; 26 (4): 551-555.

9. Ateriya N., Saraf A., Meshram V. et al. Telemedicine and virtual consultation: The Indian perspective. Natl Med J India. 2018; 31: 215-218.

10. Li H. Telemedicine and ophthalmology. Surv Ophthalmol. 1999; 44: 61-72.

11. Bashshur R., Reardon T., Shannon G. Telemedicine: A new health care delivery system. Annu Rev Public Health. 2000; 21: 613-637.

12. Allen A., Perednia D. Letter in reply to comment on their telemedicine article. JAMA. 1995; 273(6):483-488.

13. Murdoch I. Telemedicine. Br J Ophthalmol. 1999; 83 (11): 1254-1256.

14. Malay D. COVID-19, Pandemic, and Social Distancing. J Foot Ankle Surg. 2020; 59 (3): 447-448.

15. Haston W., Horsley H., Milne A. Establishing a postgraduate qualification in remote health care. J. of Telemedicine and Telecare. 1996; 2: 114-118. 